Article

\title{
Zinc Oxide Nanoparticles Promote YAP/TAZ Nuclear Localization in Alveolar Epithelial Type II Cells
}

\author{
Vincent Laiman ${ }^{1,2}$, Didik Setyo Heriyanto ${ }^{2}$, Yueh-Lun Lee ${ }^{3}$, Ching-Huang Lai ${ }^{4}{ }^{\circ}$, Chih-Hong Pan ${ }^{4,5}$,

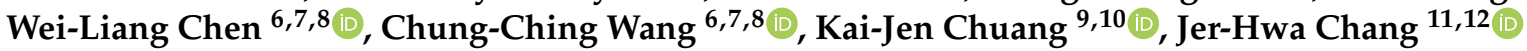 \\ and Hsiao-Chi Chuang $11,13,14, *$ (D)
}

check for updates

Citation: Laiman, V.; Heriyanto, D.S.; Lee, Y.-L.; Lai, C.-H.; Pan, C.-H.; Chen, W.-L.; Wang, C.-C.; Chuang, K.-J.; Chang, J.-H.; Chuang, H.-C. Zinc Oxide Nanoparticles Promote YAP/TAZ Nuclear Localization in Alveolar Epithelial Type II Cells. Atmosphere 2022, 13, 334. https:// doi.org/10.3390/atmos13020334

Academic Editor: Ian Colbeck

Received: 27 January 2022

Accepted: 13 February 2022

Published: 16 February 2022

Publisher's Note: MDPI stays neutral with regard to jurisdictional claims in published maps and institutional affiliations.

Copyright: (C) 2022 by the authors. Licensee MDPI, Basel, Switzerland. This article is an open access article distributed under the terms and conditions of the Creative Commons Attribution (CC BY) license (https:// creativecommons.org/licenses/by/ $4.0 /)$.
1 International PhD Program in Medicine, College of Medicine, Taipei Medical University, Taipei 11031, Taiwan; vincentharun29@gmail.com

2 Department of Anatomical Pathology, Faculty of Medicine, Public Health and Nursing, Universitas Gadjah Mada_Dr. Sardjito Hospital, Yogyakarta 55281, Indonesia; didik_setyoheriyanto@mail.ugm.ac.id

3 Department of Microbiology and Immunology, School of Medicine, College of Medicine, Taipei Medical University, Taipei 11031, Taiwan; yllee@tmu.edu.tw

4 School of Public Health, National Defense Medical Center, Taipei 11490, Taiwan; lgh@mail.ndmctsgh.edu.tw (C.-H.L.); chihhon.pan@msa.hinet.net (C.-H.P.)

5 Institute of Labor, Occupational Safety and Health, Ministry of Labor, New Taipei City 22143, Taiwan

6 Department of Family and Community Medicine, Division of Family Medicine, Tri-Service General Hospital, Taipei 11490, Taiwan; weiliang0508@gmail.com (W.-L.C.); bigching@gmail.com (C.-C.W.)

7 Department of Family and Community Medicine, Division of Geriatric Medicine, Tri-Service General Hospital, Taipei 11490, Taiwan

8 School of Medicine, National Defense Medical Center, Taipei 11490, Taiwan

9 School of Public Health, College of Public Health, Taipei Medical University, Taipei 11031, Taiwan; kjc@tmu.edu.tw

10 Department of Public Health, School of Medicine, College of Medicine, Taipei Medical University, Taipei 11031, Taiwan

11 School of Respiratory Therapy, College of Medicine, Taipei Medical University, Taipei 11031, Taiwan; m102094030@tmu.edu.tw

12 Department of Internal Medicine, Division of Pulmonary Medicine, Wan Fang Hospital, Taipei Medical University, Taipei 11696, Taiwan

13 Department of Internal Medicine, Division of Pulmonary Medicine, Shuang Ho Hospital, Taipei Medical University, New Taipei City 23561, Taiwan

14 Cell Physiology and Molecular Image Research Center, Wan Fang Hospital, Taipei Medical University, Taipei 11696, Taiwan

* Correspondence: chuanghc@tmu.edu.tw; Tel.: +886-2-2736-1661 (ext. 3512); Fax: +886-2-2739-1143

Abstract: We investigated roles of Hippo signaling pathway components in alveolar type II cells (AECII) after zinc oxide nanoparticle (ZnONP) exposure. ZnONPs physicochemistry was characterized using field emission-scanning electron microscopy (FE-SEM) and energy-dispersive X-ray (EDX) microanalysis. ZnONP deposition in human respiratory tract was estimated using multiplepath particle dosimetry (MPPD) model. MLE-12 AECII were cultured and exposed to 0, 1, and $5 \mu \mathrm{g} / \mathrm{mL}$ of ZnONPs for $24 \mathrm{~h}$. Western blots were used to investigate signaling pathways associated with Yes-associated protein (YAP)/transcriptional co-activator with PDZ-binding motif (TAZ), cell adherens junctions, differentiation, and senescence. ZnONPs morphology was irregular, with Zn and $\mathrm{O}$ identified. Approximately $72 \%$ of inhaled $\mathrm{ZnONPs}$ were deposited in lungs, with $26 \%$ being deposited in alveolar regions. ZnONP exposure increased nuclear YAP expression and decreased cytoplasmic YAP expression by AECII. Adherens junction proteins, E-cadherin, $\alpha$-catenin, and $\beta$ catenin, on AECII decreased after ZnONP exposure. ZnONP exposure of AECII increased alveolar type I (AECI) transition protein, LGALS3, and the AECI protein, T1 $\alpha$, while decreasing AECII SPC expression. ZnONP exposure induced Sirt1 and p53 senescence proteins by AECII. Our findings showed that inhalable ZnONPs can deposit in alveoli, which promotes YAP nuclear localization in AECII, resulting in decrease tight junctions, cell differentiation, and cell senescence. 
Keywords: Hippo pathway; lung deposition; nanoparticle; physicochemistry; senescence; welding fumes

\section{Introduction}

Zinc oxide $(\mathrm{ZnO})$ nanoparticles (NPs; $\mathrm{ZnONPs}$ ) are used in a variety of commercial products and industrial processes, including paints, coatings, and finishing materials [1,2]. Moreover, $\mathrm{ZnONP}$ have shown anticancer effects against various cancer cell lines and antimicrobial effects [3]. ZnO is a multifunctional material which has been extensively described previously by Wojnarowicz et al. [4]. $\mathrm{ZnO}$, for example, is used as an ultraviolet (UV) radiation filter in sunscreen cosmetics, or as an inorganic conductor in flexible and transparent devices such as transparent electrodes and flat panel displays. However, ZnONP toxicity has also been reported previously, including its hepatotoxicity, neurotoxicity, immunotoxicity, and pulmonary toxicity properties [3]. Recent reports indicated that ZnONPs in metal fumes may be an important occupational health issue for respiratory health $[5,6]$. In the United States, the permissible exposure limit (PEL) for occupational exposure to $\mathrm{ZnO}$ is $5 \mathrm{mg} / \mathrm{m}^{3}$ of respirable dust [7]. Notably, most of the particles produced during welding processes are present in the nano-sized fraction. However, the current PEL for $\mathrm{ZnO}$ is insufficient for occupational health protection. Due to their unique size fraction and large surface area, ZnONPs are of concern because they are easily transported into deeper parts of the lungs via inhalation, and they may interact with lung cells such as epithelial cells. When ZnONPs accumulate in the lungs, they were shown to cause oxidative stress and inflammation [8]. Aerosol ZnONP exposure to mice for $60 \mathrm{~min}$ at a dose of $166 \mathrm{ng} / \mathrm{cm}^{2} / \mathrm{min}$ by the head only was also reported to decrease the lung tidal volume [9]. Another study found that $\mathrm{ZnONP}$ exposure by intratracheal instillation in rats at a surface area dose of $150 \mathrm{~cm}^{2} /$ rat caused goblet cell hyperplasia, airway epithelial cell proliferation, and pulmonary fibrosis [10]. Therefore, ZnONPs are implicated as having negative roles in the pathogenesis of lung diseases, and more studies into how lung cells respond to $\mathrm{ZnONPs}$ are required.

The lungs are a complex organ with an epithelial surface area that allows for efficient gas exchange and host defense, both of which are dependent on the integrity of this epithelium [11]. Furthermore, lung tissues have progenitor cells that can be induced to proliferate and differentiate into one or more cell types in response to injury. Alveolar epithelial cells type II (AECII) are considered to be alveolar epithelial stem/progenitor cells [12]. The ability of AECII to self-renew and differentiate into alveolar epithelial type I cells (AECI) was demonstrated during both a homeostatic state and during regeneration after an injury, which contributes to new formation of the alveolar epithelium. This suggests that the ability of AECII, resident progenitor cells, to respond to lung injuries is important.

The Hippo pathway is a recently discovered pathway that has been linked to cell development, proliferation, apoptosis, and differentiation [13]. Yes-associated protein (YAP) is a signaling transcription factor that is linked to the Hippo pathway. Studies reported that YAP and transcriptional co-activator with PDZ-binding motif (TAZ), paralogous transcriptional coactivators of the Hippo pathway, regulate AECII functions following lung injury, including AECII-to-AECI differentiation, proliferation, and inflammation [12,14]. Cell junction proteins were also found to play roles in the YAP pathway. For example, $\alpha-$ catenin and E-cadherin mediate contact inhibition and decreased YAP dephosphorylation, resulting in Hippo pathway inactivation [15]. Inactivation of $\alpha$-catenin and E-cadherin facilitates the differentiation of bronchiolar progenitor cells and airway regeneration. Furthermore, decreases in YAP/TAZ were linked to the emphysematous lung phenotype in chronic obstructive pulmonary disease (COPD) [16]. When the Hippo pathway is inhibited, YAP/TAZ accumulate in nuclei where they interact with transcription factors and promote gene expressions associated with proliferation, cell survival, and differentiation. Therefore, YAP/TAZ may play critical roles in regulating AECII-to-AECI differentiation in the progression of lung diseases. 
Our previous report showed that metal fumes from a shipyard welding area decreased the cell viability of human coronary artery epithelial cells (HCAECs) while increasing levels of 8-hydroxy-2'-deoxyguanosine (8-OHdG), the proinflammatory cytokine interleukin (IL)-6, and nitric oxide (NO) [5]. Metal fumes are normally generated during industrial processes and exist as NPs with aerodynamic diameters of 10-100 nm [17]. Our previous study also found that shipyard welders were exposed to more particulate matter with an aerodynamic diameter of $\leq 2.5 \mu \mathrm{m}\left(\mathrm{PM}_{2.5}\right)$ than were office workers [18]. Furthermore, we discovered higher amounts of manganese (Mn), iron (Fe), vanadium (V), cobalt (Co), zinc $(\mathrm{Zn})$, and copper $(\mathrm{Cu})$ in personal $\mathrm{PM}_{2.5}$ samples of welding workers than in those of office workers [18]. We also found that Zn, with particle diameter of $<56 \mathrm{~nm}$, was one of the most significant metal increases observed between welding and office workers [5]. However, the underlying mechanisms involved in lung injury by metal fumes remain unclear. Therefore, we chose ZnONPs to represent one of the metal fumes in welding areas to which AECII might be exposed. The objective of this study was to investigate the roles of components of the Hippo signaling pathway in AECII after ZnONP exposure. The underlying pathways regulated by ZnONPs could be vital in understanding the regenerative process of alveolar cells.

\section{Materials and Methods}

\subsection{ZnONPs and Rreagent Sources}

The source of the ZnONPs with a spherical shape and an average diameter of $20 \mathrm{~nm}$ was Nanostructured \& Amorphous Materials (Houston, TX, USA). The purity was 99.5 wt \%, the specific surface area was $50 \mathrm{~m}^{2} / \mathrm{g}$, and the bulk density was $0.1 \mathrm{~g} / \mathrm{cm}^{3}$. All of the other reagents were obtained from Sigma (St. Louis, MO, USA) if another source is not explicitly stated.

\subsection{Characterization of $\mathrm{ZnONPS}$}

The physicochemistry of ZnONPs was characterized using an Inspect ${ }^{\mathrm{TM}}$ field emissionscanning electron microscope (FE-SEM; JEOL 2100, Akishima, Japan) and an energydispersive X-ray (EDX) microanalysis. Preparation of FE-SEM samples was as previously reported [19]. Briefly, ZnONPs were adhered onto $12 \mathrm{~mm}$ carbon sticky tabs, which were fixed on $13 \mathrm{~mm}$ aluminum SEM stubs following coating with platinum to an average thickness of $10 \mathrm{~nm}$ with a sputter coater, and then imaged. FE-SEM was operated at an accelerating voltage of $15 \mathrm{kV}$ and a $2.5 \mathrm{~nm}$ spot size. An elemental analysis for investigating chemicals (inorganics) was performed using the EDX Genesis Microanalysis System (Genesis 4000, EDAX Co., Mahwah, NJ, USA).

\subsection{Multiple-Path Particle Dosimetry (MPPD) Model}

Respiratory deposition of ZnONPs in the human respiratory tract was estimated in this study based on the MPPD model (vers. 3.04), which was developed by Applied Research Associates (Albuquerque, NM, USA) [20]. The MPPD model is an extensively used method for estimating the deposition fraction of particles in the human respiratory tract. The model provides a more accurate and realistic assessment of dosage than other models [20]. Briefly, alveolar areas in both lungs were presumed to be symmetrical. Deposition fractions were determined using a functional residual capacity of $3300 \mathrm{~mL}$, an upper respiratory tract volume of $50 \mathrm{~mL}$, a tidal volume of $625 \mathrm{~mL}$, and a breathing frequency of 12 breaths $/ \mathrm{min}$ (with minute ventilation of $7500 \mathrm{~mL}$ ). A breathing frequency of 12 breaths/min was assumed, with an inspiratory fraction of 0.5 and no pause between inhalation and exhalation. ZnONPs, which were assumed to reach the lung via the nose, come in a variety of diameters ranging from 0.01 to $1 \mu \mathrm{m}$ in size. A ZnONP bulk density of $0.1 \mathrm{~g} / \mathrm{cm}^{3}$ was used, and the aspect ratio was set to 1 (spherical). In the occupational exposure scenario, the mass concentration was $1 \mathrm{mg} / \mathrm{m}^{3}$ for $8 \mathrm{~h}$ /day for 5 days. The mass concentration of ZnONPs for an occupational setting was referenced from our previous reports [18,21]. 


\subsection{Culture of ARCII and Treatment}

MLE-12 AECII (CLR-2100) obtained from ATCC (Manassas, VA, USA) were cultured in $6 \mathrm{~cm}$ dishes using Dulbecco's modified Eagle's medium (DMEM): F-12 medium that contained $2.5 \mathrm{mM}$ L-glutamine, $15 \mathrm{mM}$ HEPES, $0.5 \mathrm{mM}$ sodium pyruvate, and $1200 \mathrm{mg} / \mathrm{L}$ sodium bicarbonate, according to the manufacturer's instructions. Cells were incubated at $37^{\circ} \mathrm{C}$ in $95 \%$ humidity and $5 \% \mathrm{CO}_{2}$. MLE-12 AECII were exposed to ZnONPs at 0 (control), 1 , and $5 \mu \mathrm{g} / \mathrm{mL}$ for $24 \mathrm{~h}$ after $24 \mathrm{~h}$ of starvation. These concentrations were selected based on a cell viability of $>80 \%$ after exposure, as determined by previous reports $[22,23]$.

\subsection{Western Blot Analysis}

Proteins were extracted from whole-cell lysates, the cytoplasm, and nuclei using a Cell Lysis Buffer and Cytoplasmic and Nuclear Protein Extraction Kit (BRARZ106, Biotools, Taipei, Taiwan). Protein concentrations were determined using the BCA Protein Assay Reagent Kit (Bio-Rad). Samples were subjected to sodium dodecylsulfate polyacrylamide gel electrophoresis (SDS-PAGE) followed by electro-transfer onto polyvinylidene difluoride (PVDF) membranes (Millipore, Darmstadt, Germany). The primary antibodies for YAP (1:1000), phosphorylated (p)-YAP (1:1000), TAZ (1:1000), p-TAZ (1:1000), Ecadherin (1:1000), $\alpha$-catenin (1:1000), $\beta$-catenin (1:1000), SPC (1:1000), LGALS3 (1:1000), T1 $\alpha$ (podoplanin; 1:1000), Sirt1 (1:1000), p53 (1:1000), lamin A/C (1:1000), and $\beta$-actin (1:1000) were obtained from Cell Signaling (Danvers, MA, USA) or Abcam (Boston, MA, USA). The secondary horseradish peroxidase (HRP)-conjugated anti-rabbit (1:2000) antibody was procured from Chemicon International (Temecula, CA, USA) and Merck Millipore (Danvers, MA, USA). After blocking and primary antibody incubation, the HRP-labeled secondary antibody was incubated and rinsed with Tris-buffered saline with $0.1 \%$ Tween ${ }^{\circledR}$ 20 detergent (TBST). Enhanced chemiluminescence Western blotting reagents were applied, and images were captured using the ChemiDoc MP imager (Bio-Rad, Hercules, CA, USA). Image-Pro vers. 4 (Media Cybernetics, Rockville, MD, USA) for Windows was used to obtain quantitative data. The obtained data were then normalized to the control (multiples of change of the control) as previously reported [24,25].

\subsection{Statistical Analysis}

Data are expressed as the mean \pm standard deviation (SD). A one-way analysis of variance (ANOVA) with Tukey's post hoc test was employed to compare multiple values. GraphPad vers. 5 for Windows was used for statistical analyses. The significance level was set to $p<0.05$.

\section{Results}

\subsection{Characterization of ZnONPs and Lung Deposition}

Figure 1a shows that ZnONPs presented with an irregular morphology. The EDX, which shows the main elements present in ZnONPs in weight\%, showed that ZnONP mainly consisted of $\mathrm{Zn}$ and minor amounts of $\mathrm{O}$. The Pt shown on the EDX results was due to the coating on the SEM stub. We next determined the deposition fractions of ZnONPs based on particle sizes in the head, tracheobronchial (TB), and alveolar regions through nasal breathing (Figure 1b). Results indicated that approximately $72 \%$ of inhaled ZnONPs were deposited in the lungs and were mainly deposited in the TB region at $32 \%$, followed by the alveolar region $(26 \%)$ and head region (12\%). Figure 1c shows that there was approximately $1.661 \times 10^{-3} \mu \mathrm{g}$ of $\mathrm{ZnONPs}$ accumulated in the alveolar region after exposure to $1 \mathrm{mg} / \mathrm{m}^{3} \mathrm{ZnONPs}$ for $8 \mathrm{~h} /$ day over 5 days.

\subsection{Expressions of Nuclear and Cytoplasmic YAP and TAZ}

Figure 2 shows expressions of nuclear and cytoplasmic YAP and TAZ and their phosphorylation on MLE cells after ZnONP exposure. We observed that expression of nuclear YAP significantly increased by ZnONP exposure $(p<0.05)$, especially at $5 \mu \mathrm{g} / \mathrm{mL}$, whereas levels of YAP in the cytoplasm significantly decreased with exposure to $5 \mu \mathrm{g} / \mathrm{mL}$ 
ZnONPs $(p<0.05)$. Expression of p-YAP significantly increased at $1 \mu \mathrm{g} / \mathrm{mL}$ ZnONPs $(p<0.05)$ compared to the control $(0 \mu \mathrm{g} / \mathrm{mL})$ or $5 \mu \mathrm{g} / \mathrm{mL} Z n O N P s$. We observed that expression of nuclear TAZ significantly increased by $1 \mu \mathrm{g} / \mathrm{mL}$ ZnONPs $(p<0.05)$, whereas the level of YAP in the cytoplasm significantly decreased by ZnONPs $(p<0.05)$. Expression of p-YAP significantly increased with exposure to $1 \mu \mathrm{g} / \mathrm{mL}$ ZnONPs $(p<0.05)$ compared to the control $(0 \mu \mathrm{g} / \mathrm{mL})$.

(a)
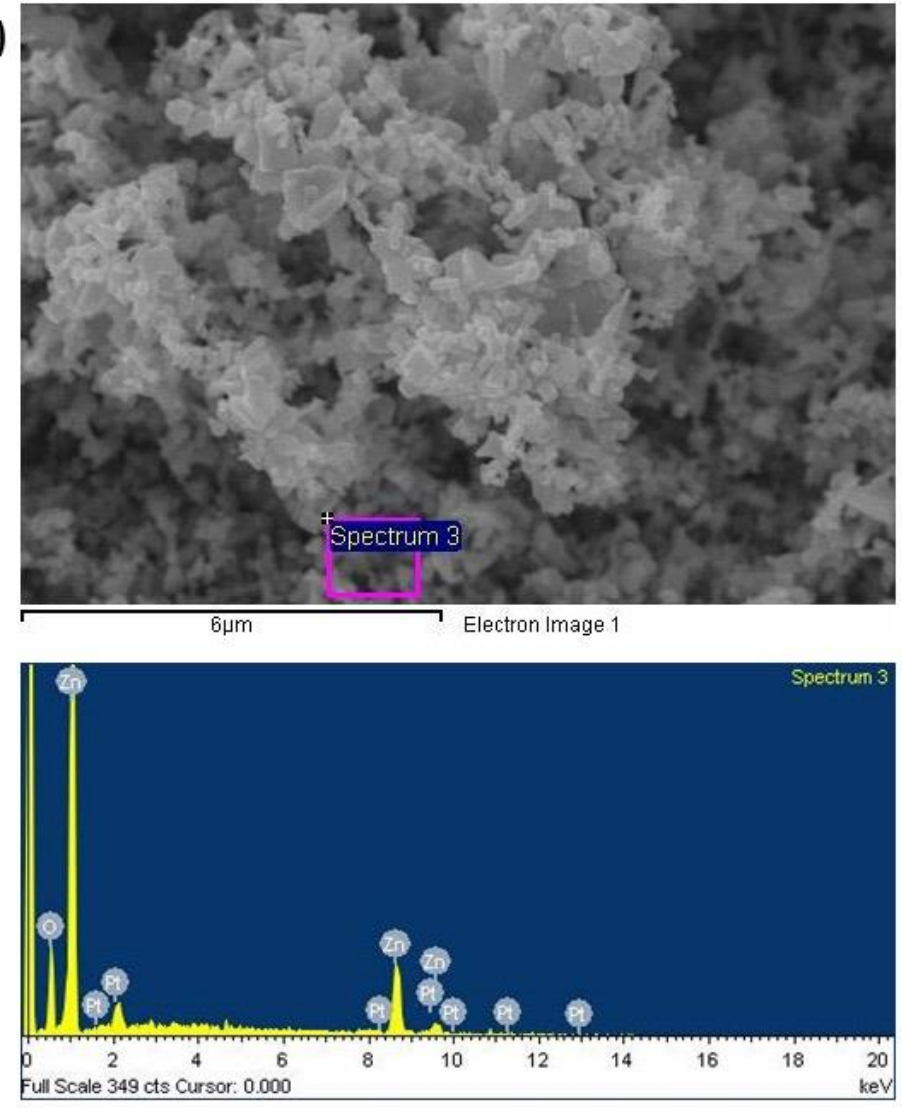

(b)

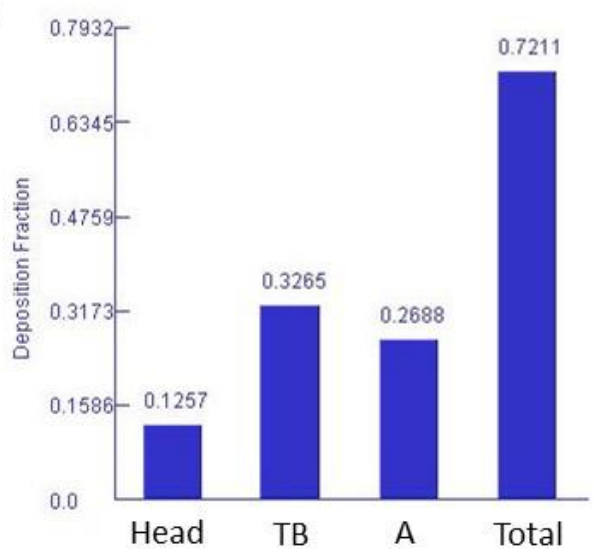

(c)

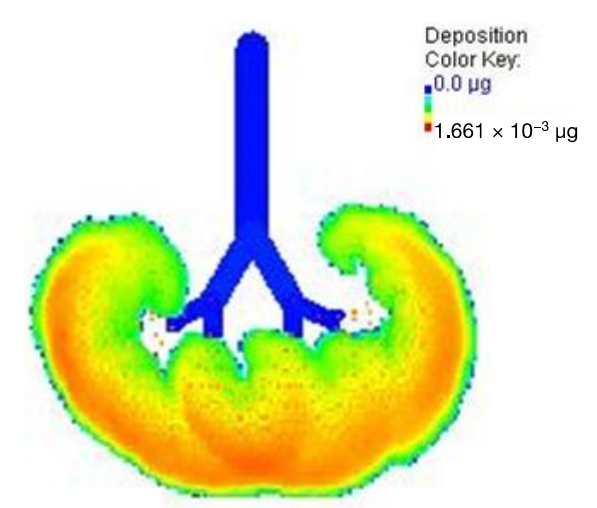

Figure 1. (a) Field emission-scanning electron microscope (FE-SEM) and energy-dispersive X-ray (EDX) spectroscopic analyses of zinc oxide nanoparticles (ZnONPs). ZnONPs had an irregular morphology, with the $\mathrm{Zn}$ and O predominating. (b) Deposition fractions of ZnONPs in the head, tracheobronchial (TB), alveolar (A), and total regions. (c) Illustration of the alveolar region showing approximately $1.661 \times 10^{-3} \mu \mathrm{g}$ of $\mathrm{ZnONPs}$ accumulated in the alveolar region after exposure to $1 \mathrm{mg} / \mathrm{m}^{3} \mathrm{ZnONPs}$ for $8 \mathrm{~h} /$ day over 5 days.

\subsection{Depletion of Junction Proteins by ZnONPs}

Figure 3 shows the expressions of junction proteins in MLE cells after ZnONP exposure. We observed that E-cadherin significantly decreased with $5 \mu \mathrm{g} / \mathrm{mL}$ ZnONPs $(p<0.05)$ compared to the control $(0 \mu \mathrm{g} / \mathrm{mL})$. Expression of $\alpha$-catenin significantly decreased by ZnONPs $(p<0.05)$, especially at $5 \mu \mathrm{g} / \mathrm{mL}$ ZnONPs. The level of $\alpha$-catenin significantly decreased by $5 \mu \mathrm{g} / \mathrm{mL}$ ZnONPs $(p<0.05)$.

\subsection{Regulation of AECII-to-AECI Transition Proteins by ZnONPs}

Figure 4 shows expressions of AECII-to-AECI transition-related proteins in MLE cells after ZnONP exposure. We found that SPC significantly decreased after exposure to ZnONPs $(p<0.05)$, especially at $5 \mu \mathrm{g} / \mathrm{mL}$ ZnONPs. The level of LGALS3 significantly increased by ZnONPs $(p<0.05)$, especially at $5 \mu \mathrm{g} / \mathrm{mL} Z \mathrm{nONPs}$. There was no statistical difference in $\mathrm{T} 1 \alpha$ with $\mathrm{ZnONP}$ exposure. 

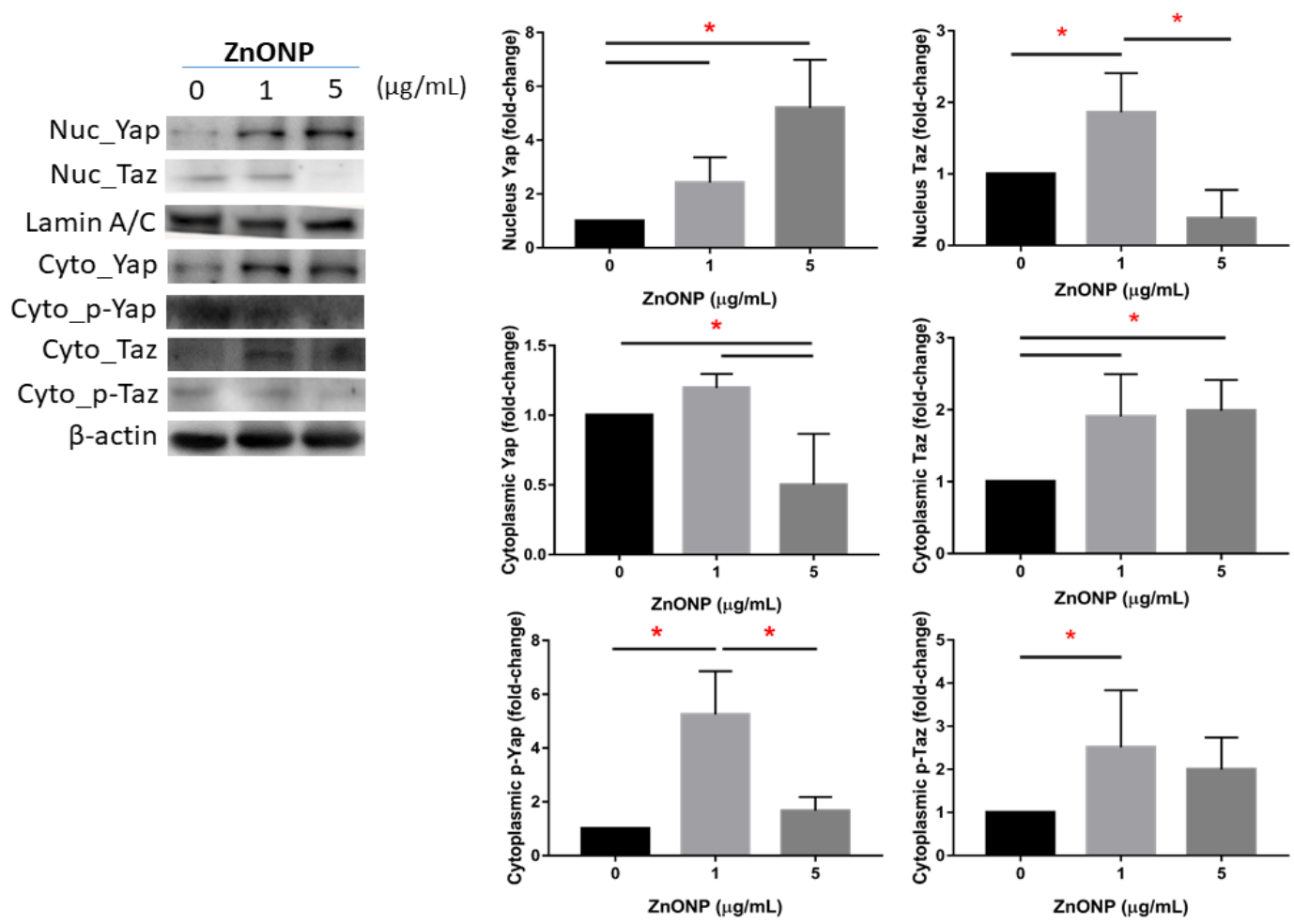

Figure 2. Expressions of Yes-associated protein (YAP), phosphorylated (p)-YAP, transcriptional coactivator with PDZ-binding motif (TAZ), and p-TAZ in nuclei and the cytoplasm of MLE-12 alveolar type II cells (AECII) after exposure to 0,1 , and $5 \mu \mathrm{g} / \mathrm{mL}$ of zinc oxide nanoparticles (ZnONPs) for 24 h. ${ }^{*} p<0.05$.
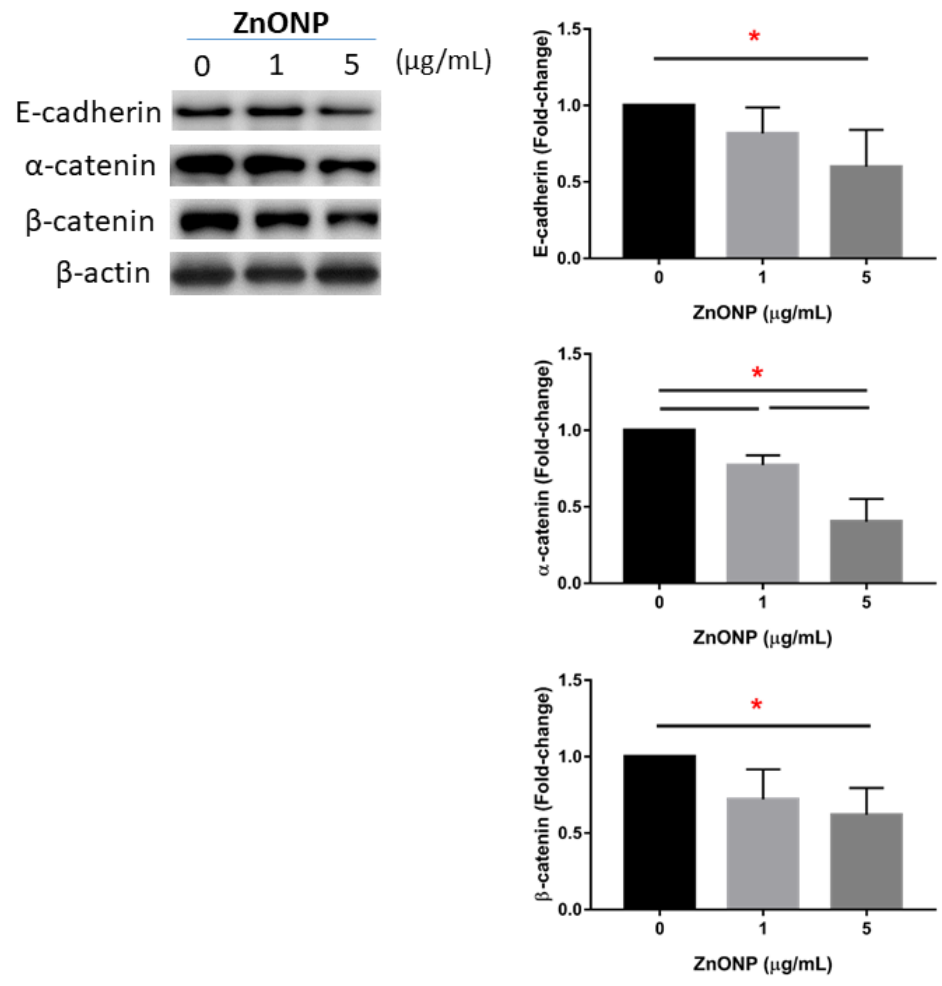

Figure 3. Expressions of E-cadherin, $\alpha$-catenin, and $\beta$-catenin by MLE-12 alveolar type II cells (AECII) after exposure to 0,1 , and $5 \mu \mathrm{g} / \mathrm{mL}$ of zinc oxide nanoparticles (ZnONPs) for $24 \mathrm{~h} .{ }^{*} p<0.05$. 

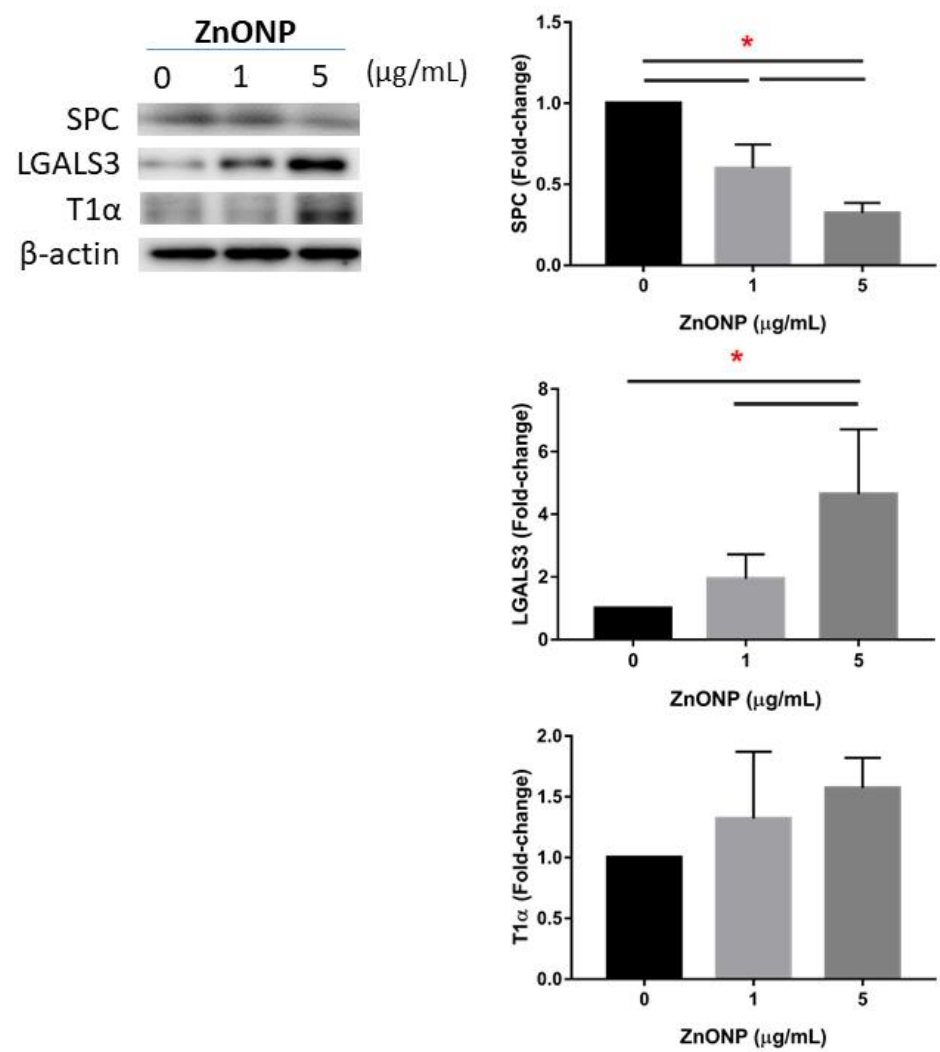

Figure 4. Expressions of SPC, LGALS3, and T1 $\alpha$ by MLE-12 alveolar type II cells (AECII) after exposure to 0,1 , and $5 \mu \mathrm{g} / \mathrm{mL}$ of zinc oxide nanoparticles (ZnONPs) for $24 \mathrm{~h}$. ${ }^{*} p<0.05$.

\subsection{Senescence and Apoptosis by ZnONPs}

Figure 5 shows expressions of Sirt1 and p53 in MLE cells after ZnONP exposure. We observed that expressions of Sirt1 and p53 significantly increased by $5 \mu \mathrm{g} / \mathrm{mL} \mathrm{ZnONP}$ $(p<0.05)$ (and $1 \mu \mathrm{g} / \mathrm{mL}$ ZnONPs for p53).

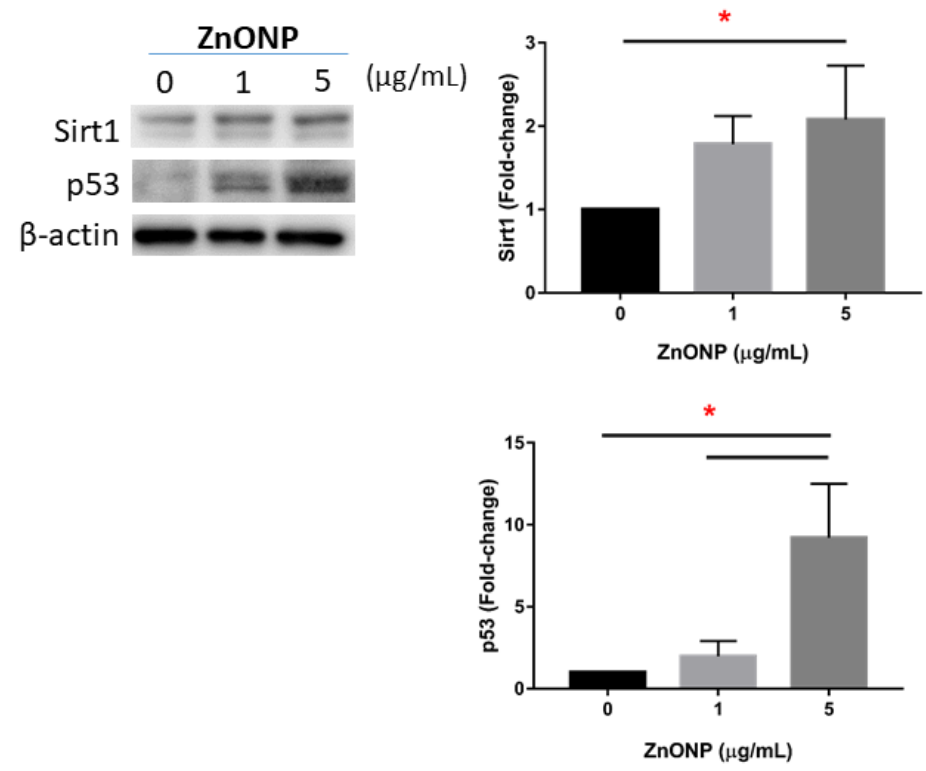

Figure 5. Expressions of Sirt1 and p53 by MLE-12 alveolar type II cells (AECII) after exposure to 0,1, and $5 \mu \mathrm{g} / \mathrm{mL}$ of zinc oxide nanoparticles (ZnONPs) for $24 \mathrm{~h} .{ }^{*} p<0.05$. 


\section{Discussion}

Pulmonary toxicity of ZnONPs from metal fumes has been previously reported [6]; however, the underlying mechanisms responsible for the Hippo pathway signaling in AECII due to ZnONP exposure remain unclear. The significance of this study is that we discovered that ZnONPs interact with AECII via the YAP/TAZ pathway, which contributes to the observed differentiation and senescence. The main findings of this study were as follows: (1) $26.8 \%$ of inhaled ZnONPs were found to be deposited in the lung of welders, (2) ZnONP exposure promoted YAP nuclear localization of AECII, and (3) ZnONPs decreased junction proteins, increased differentiation, and increased cell senescence.

The physicochemical properties of NPs play important roles in determining their toxicity, and the characteristics of ZnONPs in our study were as our previous study reported by Pan et al. [22]. That study reported on the physicochemical properties of ZnONPs, with $\mathrm{Zn}$ in a hexagonal form and its surface area, solubility, and $\mathrm{pH}$ playing important roles in its toxicity. Moreover, that study also discovered that smaller particles, including ZnONPs, had a greater surface area per unit mass than larger particles, and could induce more cell death compared to larger particles. Therefore, it is necessary to examine the adverse health effects of ZnONPs in occupational settings.

Our previous study on occupational exposure found that shipyard welders were exposed to more $\mathrm{PM}_{2.5}$ than were office workers [18]. Shipyard welders have one of the greatest at-risk occupations for developing respiratory diseases due to pollutant exposure levels. Metal fumes in shipyard welding, for example, are generally produced as NPs and are in high concentrations during the welding and cutting of galvanized sheet metal [17]. Higher levels of Mn, Fe, V, Co, Zn, and Cu were also found in the personal $\mathrm{PM}_{2.5}$ samples of shipyard welders compared to office workers in our previous study [18]. Nanoparticle Zn was also one of the most notable metal increases observed in welding workers compared to office workers. Therefore, occupational exposure to NPs is likely higher than exposure by the general population, and quantification of particle deposition in the human respiratory tract is critical for assessing health risks. We discovered that $26.8 \%$ of the ZnONPs were able to deposit in the human alveolar region in the occupational exposure scenario, which was consistent with previous reports of similar-sized NPs. In a previous study, Sprague-Dawley rats exposed to 38-nm uranium NPs via a nose-only system for $1 \mathrm{~h}$ had a lung deposition efficiency of 26.2\% [26]. Another study found that exposing Fischer rats to $17 \mathrm{~nm}$ silver NPs for $6 \mathrm{~h}$ via whole-body exposure resulted in a 24\% lung deposition efficiency [27]. NPs, including ZnONPs, can enter the trachea via the nasal and oral cavities, pass through the tracheobronchial tree, and eventually reach alveoli [28]. The quantity of transport and the position of deposition were also reported to have strong relationships with NP toxicity. Moreover, deposition efficiencies are expected to vary across the nano-size range for some regions of the respiratory tract. Together, those findings suggested that inhalable ZnONPs could deposit in the alveolar region and could impose hazardous effects on the lungs, especially in welders.

We observed that ZnONP exposure increased YAP expression in nuclei while decreasing YAP expression in the cytoplasm of ACEII. A previous study showed increased nuclear YAP/TAZ protein levels in AECII of mice 7 days after lung injury by i.n. pneumococcal infection [12]. YAP is a transcriptional coactivator and was found to be allocated in both nuclei and the cytoplasm [13]. The distribution of YAP between nuclei and the cytoplasm is dynamic, and its localization influences its function. Furthermore, YAP and its closely related paralogue, TAZ, are primary downstream mediators of the Hippo pathway [13,15]. Additionally, we observed an increase in cytoplasmic TAZ following ZnONP exposure in our study. A previous study also reported increased TAZ cytoplasmic expression in AECII of mice after lung injury by intratracheal instillation of bleomycin [29]. The finding was thought to be the process of AECII differentiation after TAZ signal activation (nuclear localization). On the other hand, we observed that ZnONP exposure reduced E-cadherin expression along with decreased $\alpha$-catenin and $\beta$-catenin expressions by AECII. Our previous study also showed that exposing pharynx epithelial cells to $1 \mathrm{mg} / \mathrm{mL}$ of 
suspended road dust $\mathrm{PM}_{2.5}$ for $24 \mathrm{~h}$ reduced E-cadherin expression [30]. Another study in Lithuania found that human bronchial epithelial cells exposed to $18 \mathrm{ng} / \mathrm{m}^{3}$ of atmospheric $\mathrm{PM}$ of $<1.0 \mu \mathrm{m}$ in aerodynamic diameter $\left(\mathrm{PM}_{1}\right)$ for $72 \mathrm{~h}$ reduced E-cadherin and $\beta$-catenin expressions [31]. E-Cadherin was previously reported to mediate contact inhibition of proliferation through the Hippo signaling pathway [15]. Inhibiting Hippo signaling could promote nuclear localization of YAP/TAZ and increase YAP/TAZ transcriptional activity. This activity causes activation of gene expressions, which are involved in cell survival, proliferation, and differentiation. Because E-cadherin is the upstream regulator of YAP, it was proposed that the absence of E-cadherin could inhibit YAP phosphorylation and subsequent ubiquitin-mediated degradation [13]. This could promote YAP interacting with its nuclear-binding partner, the transcriptional-enhanced associate domain protein (TEAD), resulting in YAP nuclear localization. On the other hand, intercellular binding of E-cadherin was also reported to result in epithelial junctional complex and tight polarized cell layer formation [15]. Moreover, inhibition of E-cadherin and $\alpha$-catenin resulted in differentiation of bronchiolar progenitor cells and regeneration of the airway [15]. $\alpha$-Catenin was reported to not directly bind to cadherin, but was linked to adhesive complexes of adherens junctions via association with $\beta$-catenin, and cells lacking the catenin protein do not adhere to each other [32]. YAP nuclear localization, therefore, occurs as a result of E-cadherin inhibition, and this could reduce AECII tight junctions, activate AECII cell differentiation, and cause AECII cell senescence $[13,33]$. Taken together, those findings suggest that ZnONP exposure may inhibit the Hippo pathway, which leads to YAP nuclear localization and subsequent downstream effects.

ZnONP exposure decreased SPC expression and increased LGALS3 and T1 $\alpha$ expressions. SPC is a marker for AECII [11]. $\mathrm{SPC}^{+} \mathrm{AECII}$ act as progenitor cells in alveoli, regulating proliferation and differentiating into $\mathrm{AECI}$ in response to lung injury [12]. T1 $\alpha$, on the other hand, is a differentiation gene that is highly expressed by type I alveolar epithelial cells, which line the majority of gas-exchange surfaces of the lungs [34]. The Hippo signaling pathway was also found to be involved in this regenerative process of AECII. LGALS3 was reported to be involved in acute inflammatory responses, and its expression was linked to alveolar injury as a marker of the pre-alveolar type 1 transitional cell state [35]. T1 $\alpha$, however, was not expressed by AECII after ZnONP exposure. Therefore, ZnONPs led AECII to the pre-alveolar type 1 transitional cell state with increasing LGALS3 expression. Our results showed that accumulation of YAP/TAZ could result in AECII cell differentiation, but in the pre-alveolar type 1 transitional cell state.

We found that ZnONP exposure increased expressions of Sirt1 and p53. A previous study found increased Sirt1 expression in mouse AECII cells exposed to 200 and $400 \mu \mathrm{M}$ paraquat, a herbicide, for $24 \mathrm{~h}$ [36]. Cellular senescence is a physiological phenotype characterized by permanent cell cycle arrest, and studies suggested that Sirt1 plays an important role in delaying cellular senescence and extending organismal lifespans [37,38]. Sirt1 upregulation was also linked to a protective mechanism that prevents airway disorders [36,39]. This implies that Sirt1 activation is aimed at preventing the development of senescence. A previous study found that human A549 lung epithelial cells exposed to $\mathrm{ZnO}$ nanorods exhibited significantly increased activity of the p53 cell cycle checkpoint protein [40]. Exposure of human A549 lung epithelial cells to $20 \mathrm{~nm}$ ZnONPs was also previously reported to increase p53 expression [22]. Another study found distinct aging features, including stem cell loss, in a mouse model of p53 created to mimic p53 activation [41]. The p53 protein is suggested to be capable of activating cell cycle checkpoints, and its induction was reported to be critical for establishing senescence. Together, these findings suggest that exposure to ZnONPs activates cell senescence in AECII.

\section{Conclusions}

In conclusion, significant amounts of ZnONPs are able to deposit in alveoli after inhalation. Inhalable ZnONPs promoted YAP nuclear localization in AECII, resulting in decreased tight junctions and increased cell differentiation and cell senescence. Our 
findings suggest that ZnONPs in welding fumes may pose adverse respiratory effects to welders.

Author Contributions: Conceptualization, C.-H.L., C.-H.P. and H.-C.C.; Data curation, V.L., W.-L.C. and C.-C.W.; Investigation, V.L. and H.-C.C.; Methodology, C.-H.L., C.-H.P. and H.-C.C.; Software, C.-H.L., C.-H.P., K.-J.C., J.-H.C. and H.-C.C.; Supervision, C.-H.L. and H.-C.C.; Validation, K.-J.C. and J.-H.C.; Visualization, V.L. and H.-C.C.; Writing-original draft, V.L., W.-L.C. and C.-C.W.; Writingreview \& editing, D.S.H., Y.-L.L. and H.-C.C. All authors have read and agreed to the published version of the manuscript.

Funding: This study was funded by the Ministry of Science and Technology of Taiwan (MOST 109-2314-B-038-093-MY3).

Institutional Review Board Statement: Not applicable.

Informed Consent Statement: Not applicable.

Data Availability Statement: The datasets used and/or analyzed during the current study are available from the corresponding author on reasonable request.

Acknowledgments: The authors wish to thank Yi-Syuan Lin for technical assistance with this research.

Conflicts of Interest: The authors declare no conflict of interest.

\section{References}

1. Pinnell, S.R.; Fairhurst, D.; Gillies, R.; Mitchnick, M.A.; Kollias, N. Microfine Zinc Oxide is a Superior Sunscreen Ingredient to Microfine Titanium Dioxide. Dermatol. Surg. 2000, 26, 309-314. [CrossRef]

2. Monsé, C.; Hagemeyer, O.; Raulf, M.; Jettkant, B.; van Kampen, V.; Kendzia, B.; Gering, V.; Kappert, G.; Weiss, T.; Ulrich, N.; et al. Concentration-dependent systemic response after inhalation of nano-sized zinc oxide particles in human volunteers. Part. Fibre Toxicol. 2018, 15, 8. [CrossRef]

3. Keerthana, S.; Kumar, A. Potential risks and benefits of zinc oxide nanoparticles: A systematic review. Crit. Rev. Toxicol. 2020, 50, 47-71. [CrossRef] [PubMed]

4. Wojnarowicz, J.; Chudoba, T.; Lojkowski, W. A Review of Microwave Synthesis of Zinc Oxide Nanomaterials: Reactants, Process Parameters and Morphologies. Nanomaterials 2020, 10, 1086. [CrossRef]

5. $\quad$ Lai, C.-Y.; Lai, C.-H.; Chuang, H.-C.; Pan, C.-H.; Yen, C.-C.; Lin, W.-Y.; Chen, J.-K.; Lin, L.-Y.; Chuang, K.-J. Physicochemistry and cardiovascular toxicity of metal fume PM2.5: A study of human coronary artery endothelial cells and welding workers. Sci. Rep. 2016, 6, 33515. [CrossRef] [PubMed]

6. Chuang, H.-C.; Juan, H.-T.; Chang, C.-N.; Yan, Y.-H.; Yuan, T.-H.; Wang, J.-S.; Chen, H.-C.; Hwang, Y.-H.; Lee, C.-H.; Cheng, T.-J. Cardiopulmonary toxicity of pulmonary exposure to occupationally relevant zinc oxide nanoparticles. Nanotoxicology 2013, 8, 593-604. [CrossRef] [PubMed]

7. NIOSH. National Institute for Occupational Safety and Health Pocket Guide to Chemical Hazards; NIOSH Publications; NIOSH: Cincinnati, OH, USA, 2007.

8. Jacobsen, N.R.; Stoeger, T.; van den Brule, S.; Saber, A.T.; Beyerle, A.; Vietti, G.; Mortensen, A.; Szarek, J.; Budtz, H.C.; Kermanizadeh, A.; et al. Acute and subacute pulmonary toxicity and mortality in mice after intratracheal instillation of $\mathrm{ZnO}$ nanoparticles in three laboratories. Food Chem. Toxicol. 2015, 85, 84-95. [CrossRef] [PubMed]

9. Larsen, S.T.; Da Silva, E.; Hansen, J.S.; Jensen, A.C.Ø.; Koponen, I.K.; Sørli, J.B. Acute Inhalation Toxicity after Inhalation of ZnO Nanoparticles: Lung Surfactant Function Inhibition In Vitro Correlates with Reduced Tidal Volume in Mice. Int. J. Toxicol. 2020, 39, 321-327. [CrossRef]

10. Cho, W.-S.; Duffin, R.; Howie, S.E.M.; Scotton, C.J.; Wallace, W.A.H.; MacNee, W.; Bradley, M.; Megson, I.L.; Donaldson, K. Progressive severe lung injury by zinc oxide nanoparticles; the role of $\mathrm{Zn}^{2+}$ dissolution inside lysosomes. Part. Fibre Toxicol. 2011, 8, 27. [CrossRef] [PubMed]

11. Barkauskas, C.E.; Cronce, M.J.; Rackley, C.R.; Bowie, E.J.; Keene, D.R.; Stripp, B.R.; Randell, S.H.; Noble, P.W.; Hogan, B.L.M. Type 2 alveolar cells are stem cells in adult lung. J. Clin. Investig. 2013, 123, 3025-3036. [CrossRef] [PubMed]

12. LaCanna, R.; Liccardo, D.; Zhang, P.; Tragesser, L.; Wang, Y.; Cao, T.; Chapman, H.A.; Morrisey, E.E.; Shen, H.; Koch, W.J.; et al. Yap/Taz regulate alveolar regeneration and resolution of lung inflammation. J. Clin. Investig. 2019, 129, 2107-2122. [CrossRef]

13. Zou, R.; Xu, Y.; Feng, Y.; Shen, M.; Yuan, F.; Yuan, Y. YAP nuclear-cytoplasmic translocation is regulated by mechanical signaling, protein modification, and metabolism. Cell Biol. Int. 2020, 44, 1416-1425. [CrossRef] [PubMed]

14. Isago, H.; Mitani, A.; Mikami, Y.; Horie, M.; Urushiyama, H.; Hamamoto, R.; Terasaki, Y.; Nagase, T. Epithelial Expression of YAP and TAZ Is Sequentially Required in Lung Development. Am. J. Respir. Cell Mol. Biol. 2020, 62, 256-266. [CrossRef] [PubMed]

15. Kim, N.G.; Koh, E.; Chen, X.; Gumbiner, B.M. E-cadherin mediates contact inhibition of proliferation through Hippo signalingpathway components. Proc. Natl. Acad. Sci. USA 2011, 108, 11930-11935. [CrossRef] 
16. Lin, C.; Yao, E.; Zhang, K.; Jiang, X.; Croll, S.; Thompson-Peer, K.; Chuang, P.-T. YAP is essential for mechanical force production and epithelial cell proliferation during lung branching morphogenesis. eLife 2017, 6, e21130. [CrossRef] [PubMed]

17. Chuang, K.-J.; Pan, C.-H.; Su, C.-L.; Lai, C.-H.; Lin, W.-Y.; Ma, C.-M.; Ho, S.-C.; Bien, M.-Y.; Chen, C.-H.; Chuang, H.-C. Urinary neutrophil gelatinase-associated lipocalin is associated with heavy metal exposure in welding workers. Sci. Rep. 2016, 5, 18048. [CrossRef]

18. Lai, C.H.; Chou, C.C.; Chuang, H.C.; Lin, G.J.; Pan, C.H.; Chen, W.L. Receptor for advanced glycation end products in relation to exposure to metal fumes and polycyclic aromatic hydrocarbon in shipyard welders. Ecotoxicol. Environ. Saf. 2020, 202, 110920. [CrossRef] [PubMed]

19. Chuang, H.C.; Jones, T.P.; Lung, S.C.; BéruBé, K.A. Soot-driven reactive oxygen species formation from incense burning. Sci. Total Environ. 2011, 409, 4781-4787. [CrossRef] [PubMed]

20. Asgharian, B.; Hofmann, W.; Bergmann, R. Particle Deposition in a Multiple-Path Model of the Human Lung. Aerosol Sci. Technol. 2001, 34, 332-339. [CrossRef]

21. Lai, C.H.; Ho, S.C.; Pan, C.H.; Chen, W.L.; Wang, C.C.; Liang, C.W.; Chien, C.Y.; Riediker, M.; Chuang, K.J.; Chuang, H.C. Chronic exposure to metal fume $\mathrm{PM}(2.5)$ on inflammation and stress hormone cortisol in shipyard workers: A repeat measurement study. Ecotoxicol. Environ. Saf. 2021, 215, 112144. [CrossRef] [PubMed]

22. Pan, C.-H.; Liu, W.-T.; Bien, M.-Y.; Lin, I.C.; Hsiao, T.-C.; Ma, C.-M.; Lai, C.-H.; Chen, M.-C.; Chuang, K.-J.; Chuang, H.-C. Effects of size and surface of zinc oxide and aluminum-doped zinc oxide nanoparticles on cell viability inferred by proteomic analyses. Int. J. Nanomed. 2014, 9, 3631-3643. [CrossRef]

23. Wilson, M. Interactions between Ultrafine Particles and Transition Metals in Vivo and in Vitro. Toxicol. Appl. Pharmacol. 2002, 184, 172-179. [CrossRef] [PubMed]

24. Chen, B.C.; Chang, Y.S.; Kang, J.C.; Hsu, M.J.; Sheu, J.R.; Chen, T.L.; Teng, C.M.; Lin, C.H. Peptidoglycan induces nuclear factor-kappaB activation and cyclooxygenase-2 expression via Ras, Raf-1, and ERK in RAW 264.7 macrophages. J. Biol. Chem. 2004, 279, 20889-20897. [CrossRef] [PubMed]

25. Bai, K.J.; Chuang, K.J.; Chen, C.L.; Jhan, M.K.; Hsiao, T.C.; Cheng, T.J.; Chang, L.T.; Chang, T.Y.; Chuang, H.C. Microglial activation and inflammation caused by traffic-related particulate matter. Chem.-Biol. Interact. 2019, 311, 108762. [CrossRef] [PubMed]

26. Petitot, F.; Lestaevel, P.; Tourlonias, E.; Mazzucco, C.; Jacquinot, S.; Dhieux, B.; Delissen, O.; Tournier, B.B.; Gensdarmes, F.; Beaunier, P.; et al. Inhalation of uranium nanoparticles: Respiratory tract deposition and translocation to secondary target organs in rats. Toxicol. Lett. 2013, 217, 217-225. [CrossRef]

27. Takenaka, S.; Karg, E.; Roth, C.; Schulz, H.; Ziesenis, A.; Heinzmann, U.; Schramel, P.; Heyder, J. Pulmonary and systemic distribution of inhaled ultrafine silver particles in rats. Environ. Health Perspect. 2001, 109, 547-551. [CrossRef]

28. Qiao, H.; Liu, W.; Gu, H.; Wang, D.; Wang, Y. The Transport and Deposition of Nanoparticles in Respiratory System by Inhalation. J. Nanomater. 2015, 2015, 2. [CrossRef]

29. Sun, T.; Huang, Z.; Zhang, H.; Posner, C.; Jia, G.; Ramalingam, T.R.; Xu, M.; Brightbill, H.; Egen, J.G.; Dey, A.; et al. TAZ is required for lung alveolar epithelial cell differentiation after injury. JCI Insight 2019, 4, e128674. [CrossRef] [PubMed]

30. Tung, N.T.; Ho, K.-F.; Niu, X.; Sun, J.; Shen, Z.; Wu, F.; Cao, J.; Dung, H.B.; Thuy, T.P.C.; Hsiao, T.-C.; et al. Loss of E-cadherin due to road dust PM2.5 activates the EGFR in human pharyngeal epithelial cells. Environ. Sci. Pollut. Res. 2021, 28, 53872-53887. [CrossRef]

31. Raudoniute, J.; Stasiulaitiene, I.; Kulvinskiene, I.; Bagdonas, E.; Garbaras, A.; Krugly, E.; Martuzevicius, D.; Bironaite, D.; Aldonyte, R. Pro-inflammatory effects of extracted urban fine particulate matter on human bronchial epithelial cells BEAS-2B. Environ. Sci. Pollut. Res. 2018, 25, 32277-32291. [CrossRef] [PubMed]

32. Niessen, C.M.; Leckband, D.; Yap, A.S. Tissue Organization by Cadherin Adhesion Molecules: Dynamic Molecular and Cellular Mechanisms of Morphogenetic Regulation. Physiol. Rev. 2011, 91, 691-731. [CrossRef]

33. Santinon, G.; Brian, I.; Pocaterra, A.; Romani, P.; Franzolin, E.; Rampazzo, C.; Bicciato, S.; Dupont, S. dNTP metabolism links mechanical cues and YAP/TAZ to cell growth and oncogene-induced senescence. EMBO J. 2018, 37. [CrossRef] [PubMed]

34. Ramirez, M.I.; Millien, G.; Hinds, A.; Cao, Y.; Seldin, D.C.; Williams, M.C. T1 $\alpha$, a lung type I cell differentiation gene, is required for normal lung cell proliferation and alveolus formation at birth. Dev. Biol. 2003, 256, 62-73. [CrossRef]

35. Kobayashi, Y.; Tata, A.; Konkimalla, A.; Katsura, H.; Lee, R.F.; Ou, J.; Banovich, N.E.; Kropski, J.A.; Tata, P.R. Persistence of a regeneration-associated, transitional alveolar epithelial cell state in pulmonary fibrosis. Nat. Cell Biol. 2020, 22, 934-946. [CrossRef]

36. Ding, Y.-W.; Zhao, G.-J.; Li, X.-L.; Hong, G.-L.; Li, M.-F.; Qiu, Q.-M.; Wu, B.I.N.; Lu, Z.-Q. SIRT1 exerts protective effects against paraquat-induced injury in mouse type II alveolar epithelial cells by deacetylating NRF2 in vitro. Int. J. Mol. Med. 2016, 37, 1049-1058. [CrossRef] [PubMed]

37. Lee, S.-H.; Lee, J.-H.; Lee, H.-Y.; Min, K.-J. Sirtuin signaling in cellular senescence and aging. BMB Rep. 2019, 52, 24-34. [CrossRef] [PubMed]

38. Ota, H.; Akishita, M.; Eto, M.; Iijima, K.; Kaneki, M.; Ouchi, Y. Sirt1 modulates premature senescence-like phenotype in human endothelial cells. J. Mol. Cell. Cardiol. 2007, 43, 571-579. [CrossRef] [PubMed]

39. Lai, T.; Wen, X.; Wu, D.; Su, G.; Gao, Y.; Chen, C.; Wu, W.; Lv, Y.; Chen, Z.; Lv, Q.; et al. SIRT1 protects against urban particulate matter-induced airway inflammation. Int. J. Chronic Obstr. Pulm. Dis. 2019, 14, 1741-1752. [CrossRef] [PubMed] 
40. Ahamed, M.; Akhtar, M.J.; Raja, M.; Ahmad, I.; Siddiqui, M.K.J.; AlSalhi, M.S.; Alrokayan, S.A. ZnO nanorod-induced apoptosis in human alveolar adenocarcinoma cells via p53, survivin and bax/bcl-2 pathways: Role of oxidative stress. Nanomed. Nanotechnol. Biol. Med. 2011, 7, 904-913. [CrossRef] [PubMed]

41. Liu, D.; Ou, L.; Clemenson, G.D.; Chao, C.; Lutske, M.E.; Zambetti, G.P.; Gage, F.H.; Xu, Y. Puma is required for p53-induced depletion of adult stem cells. Nat. Cell Biol. 2010, 12, 993-998. [CrossRef] [PubMed] 